\title{
Environmental fate of the anti-parasitic ivermectin in an aquatic micro-ecological system after a single oral administration
}

\author{
Di Wang ${ }^{1}$, Bing Han ${ }^{2}$, Shaowu $\mathrm{Li}^{1}$, Yongsheng Cao ${ }^{1}$, Xue Du ${ }^{1}$, Tongyan Lu ${ }^{\text {Corresp. } 1}$ \\ ${ }^{1}$ Department of Fish Diseases, Heilongjiang River Fisheries Research Institute, Chinese Academy of Fishery Sciences, Harbin/Heilongjiang, China \\ Department of Pharmacology, School of Medicine, Southeast University, Nanjing/Jiangsu, China \\ Corresponding Author: Tongyan Lu \\ Email address: lutongyan@hrfri.ac.cn
}

Background. Ivermectin (IVM) has been widely used in the aquaculture industry since its efficacy against parasites. However, the degradation of IVM was very slow in aquatic environments and the environmental fate of IVM in a complete aquatic system was still not clear. Therefore, comparable studies in a complete aquatic system were merited and helped to elucidate the environmental fate and effects of IVM.

Methods. An aquatic micro-ecological system containing an aquatic environment (water and sediment) and aquatic organisms (invertebrates, aquatic plants and fish) was built to simulate the natural rearing conditions. A single dose of $0.3 \mathrm{mg} \cdot \mathrm{kg}-1$ body weight of IVM was given to the fish by oral gavage. Water, sediment, the roots and leaves of the aquatic plants, the soft tissue of the invertebrates and the visceral mass and muscle of fish samples were collected at 0.5 hours, 1 day, 7 days, 15 days, 30 days, 45 days, 60 days and 70 days after the treatment. IVM concentration in each sample was determined using ELISA method.

Results. IVM was quickly and widely distributed into the whole aquatic system in one day, and then was highly accumulated in organisms resulting in long-term residues. IVM was exchanged multiple times between the different media, which caused continuous fluctuations in the concentration of IVM in the water and sediment. It was worth noting that there was a second peak value of IVM in the fish and invertebrates after 30 days. The environmental fate of the IVM in the aquatic micro-ecological system showed that the drug was transferred from the fish to aquatic plants in the first seven days, and then gathered in the water and sediment, finally accumulating in the invertebrates. Our results indicated that an effective aquatic micro-ecological system was successfully established, and it could be applied to the study the environmental fate of IVM, which will aid the scientific use of this anti-parasitic agent during aquaculture. 
1 Environmental fate of the anti-parasitic ivermectin in

2 an aquatic micro-ecological system after a single oral

3 administration

4

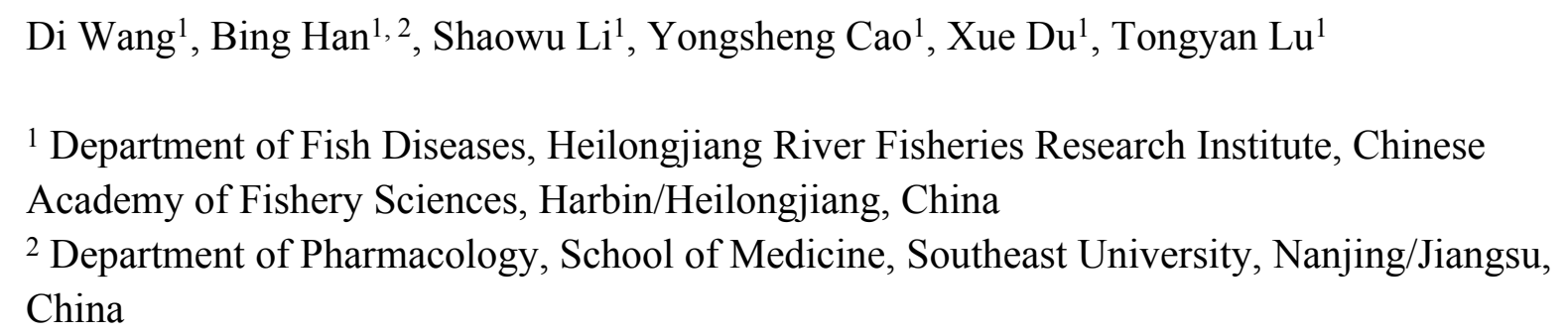

${ }^{1}$ Department of Fish Diseases, Heilongjiang River Fisheries Research Institute, Chinese Academy of Fishery Sciences, Harbin/Heilongjiang, China

${ }^{2}$ Department of Pharmacology, School of Medicine, Southeast University, Nanjing/Jiangsu,

\section{Abstract}

Background. Ivermectin (IVM) has been widely used in the aquaculture industry since its efficacy against parasites. However, the degradation of IVM was very slow in aquatic environments and the environmental fate of IVM in a complete aquatic system was still not clear. Therefore, comparable studies in a complete aquatic system were merited and helped to elucidate the environmental fate and effects of IVM.

Methods. An aquatic micro-ecological system containing an aquatic environment (water and sediment) and aquatic organisms (invertebrates, aquatic plants and fish) was built to simulate the natural rearing conditions. A single dose of $0.3 \mathrm{mg} \cdot \mathrm{kg}-1$ body weight of IVM was given to the fish by oral gavage. Water, sediment, the roots and leaves of the aquatic plants, the soft tissue of the invertebrates and the visceral mass and muscle of fish samples were collected at 0.5 hours, 1 day, 7 days, 15 days, 30 days, 45 days, 60 days and 70 days after the treatment. IVM concentration in each sample was determined using ELISA method.

Results. IVM was quickly and widely distributed into the whole aquatic system in one day, and then was highly accumulated in organisms resulting in long-term residues. IVM was exchanged multiple times between the different media, which caused continuous fluctuations in the concentration of IVM in the water and sediment. It was worth noting that there was a second peak value of IVM in the fish and invertebrates after 30 days. The environmental fate of the IVM in the aquatic micro-ecological system showed that the drug was transferred from the fish to aquatic plants in the first seven days, and then gathered in the water and sediment, finally accumulating in the invertebrates. Our results indicated that an effective aquatic micro-ecological system was successfully established, and it could be applied to the study the environmental fate of IVM, which will aid the scientific use of this anti-parasitic agent during aquaculture. 
40

41

42

43

44

45

46

47

48

49

50

51

52

53

54

55

56

57

58

59

60

61

62

63

64

65

66

67

68

69

70

71

72

73

74

75

76

77

78

79

\section{Introduction}

With the increasing awareness of food and environmental security, public concern and scientific studies on pharmaceutical drugs in the environment have increased over the previous years. Ivermectin (IVM) is a macrocyclic lactone derived from avermectins (AVMs), which is comprised of two homologues ( $\geqslant 80 \% 22,23$-dihydroavermectin $\mathrm{B}_{1 \mathrm{a}}$ and $\leqslant 20 \% 22,23$ dihydroavermectin $\mathrm{B}_{1 \mathrm{~b}}$ ) (Rath et al., 2016). As a class of broad-spectrum agents with the ability to kill endo- and ectoparasites (Omura, 2008), IVM has been primarily been used throughout the world to treat livestock (sheep, swine and horse) and pets to protect them against a broad variety of parasites only a few years after it was first made legal in 1981 (Geary, 2005). In particular, IVM (as Mectizan ${ }^{\circledR}$ ) was employed to control and eliminate onchocerciasis for humans in poor rural communities in Africa and South America from 1987, and the Mectizan Donation Program administered 168 million treatments in 2013 (Omura et al., 2014).

Since its efficacy against sea lice infections in farmed Atlantic salmon (Salmo salar L.) without any treatment-associated host mortality was documented in 1987 (Palmer et al., 1987), IVM has been widely used in the aquaculture industry (Prasse et al., 2009). Although the drug tolerance was species dependent (Wu et al., 2012), IVM had a narrow gap (between safe and toxic doses) in salmon and was highly toxic to freshwater aquatic species (Garric et al., 2007; Ucan-Marin et al., 2012). The degradation of IVM was very slow in aquatic environments, and the degradation rate in the sediment was only $28.3 \%$ after 70 days in a simulated river way environment (Wu et al., 2012), while its half-life in marine sediment was greater than 100 days (Davies et al., 1998). Due to its hydrophobic property and high affinity to organic matter (Bloom et al., 1993), the long-term accumulation of IVM in the aquaculture environment was recognized as the diffusion sources of pollutants affecting ecosystems.

Wall et al. (1987) reported that IVM could kill beneficial dung-degrading insects (Coleoptera sp. and Scarabaeidae sp.) when calves were treated with the recommended dose. In view of this situation, scientific researchers more closely examined the ecological fate and effects of IVM on the environment. In 2007, the standardized test methodology (mesocosm) of IVM potential environmental risk was created to evaluate the fate and exchange between water and sediment. The acute effects, chronic responses and long-term effects of IVM could be identified by this method (Sanderson et al., 2007). Following this, a test system, containing a cooling and water trap, was built to investigate the environmental fate of IVM in an aerobic sediment/water system. IVM could be rapidly sorbed to the sediment, converted into bound residues and transferred into several transformation products (TPs) (Prasse et al., 2009). In addition, the fate and effects of IVM on soil invertebrates in terrestrial model ecosystems were assessed in Terrestrial Model Ecosystems (TMEs), and the results showed that IVM generally had low to moderate effects on soil organisms (Forster et al., 2011). Moreover, Rath et al. (2016) found that IVM was difficult to desorb once sorbed to the soil, and the sorption parameters were dependent on the IVM concentration. IVM degradation by $\mathrm{UV} / \mathrm{TiO}_{2}$ and $\mathrm{UV} / \mathrm{TiO}_{2} / \mathrm{H} 2 \mathrm{O}_{2}$ was highly effective in water. All the studies described above were focused on the sorption, degradation and toxicity of IVM to the soil, sediment and invertebrates. Therefore, comparable 
80

81

82

83

84

85

86

87

88

89

90

91

92

93

94

95

96

97

98

99

100

101

102

103

104

105

106

107

108

109

110

111

112

113

114

115

116

117

118

119

studies in a complete aquatic system were merited and helped to elucidate the environmental fate and effects of IVM. In this study, we evaluated the fate of IVM in a simulated aquatic microecological system containing an aquatic environment (water and sediment) and aquatic organisms (invertebrates, aquatic plants and fish).

\section{Materials \& Methods}

\section{Compound}

IVM (99.5\%) was purchased from Dr. Ehrenstorfer GmbH (Augsburg, Germany; Lot No. 10506). Acetonitrile and ethyl acetate (HPLC grade) were purchased from Merck KGaA (Darmstadt, Germany). Dimethyl sulfoxide (ACS grade) was purchased from Amresco (Ohio, USA). $\mathrm{NaCl}$ and $\mathrm{MgSO}_{4}$ (analytical grade) were purchased from Aladdin (Shanghai, China). An avermectins ELISA Kit was purchased from Randox (Crumlin, United Kingdom; Cat No. AV3477).

\section{Construction of the simulated aquatic micro-ecological system}

The study was conducted during the spring/summer at a temperature of $20-25^{\circ} \mathrm{C}$ in Northeast China. The system was located in an open area without differentiated shading or wind exposure close to the aquaculture ponds. $5 \mathrm{~cm}$ thick sediment and 300 liters water, which were obtained from Hulan Aquaculture Experimental Station (Harbin, China), were added to a 400 liter polypropylene tank to build the simulated aquatic micro-ecological system. Three parallels were set up in the experiment. Forty brocarded carp (Cyprinus carpio haematopterus) with a mean body weight of $5.35 \pm 0.48 \mathrm{~g}, 40$ mudsnails (Cipangopaludina cahayensis) and 40 Amazon sword plants (Echinodorus amazonicus) with a mean length of 9-12 cm were placed into each system as shown in Fig. 1.

The system, with no IVM added or detected, was equilibrated for seven days in natural conditions. The water quality was tested daily and had a $\mathrm{pH}$ of approximately 7 , while the oxygen level was $>6 \mathrm{mg} \cdot \mathrm{L}^{-1}$ due to the inflation pump. The water was replenished every two days.

\section{Treatment and experimental design}

After the systems were stable, the experimental fish were subjected to IVM at a single dose of $0.3 \mathrm{mg} \cdot \mathrm{kg}^{-1}$ body weight by oral gavage (Yang., 2005). The fish were starved at least for $24 \mathrm{~h}$ to ensure gut clearance before the oral administration. The samples, including the roots and leaves of the Amazon sword plant, the visceral mass and muscle of the brocarded carp, the soft tissue of the mudsnails, and the sediment and water $(n=3)$, were collected at the following time intervals respectively: 0.5 hour, 1, 7, 15, 30, 45, 60 and 70 days. For water, $2 \mathrm{~mL}$ water from upper, middle and lower layer were sampled and mixed to be tested. For sediment, a $1 \mathrm{~cm}$ diameter casing was used to vertically take the bottom mud and mix it to be tested. For Amazon sword plants, 3 plants were took randomly and the soil around the roots was discarded. After that the leaves and roots were sampled respectively. For brocarded carp, 3 fish were collected randomly and the visecral mass and muscle were sampled. For mudsnails, 3 mudsnails were collected randomly and the shells were peeled off. The internal tissues were then sampled. All the samples were frozen immediately at $-80^{\circ} \mathrm{C}$ until assayed. 
120

121

122

123

124

125

126

127

128

129

130

131

132

133

134

135

136

137

138

139

140

141

142

143

144

145

146

147

148

149

150

151

152

153

154

155

156

157

158

159

\section{Sample preparation}

Water: A $5 \mathrm{~mL}$ water sample was centrifuged at 4,000 rpm for 10 minutes. $3 \mathrm{~mL}$ of supernatant was transferred to a new centrifuge tube. One volume ethyl acetate was added, and the mixture was vortexed for $10 \mathrm{~min}$ and centrifuged at $4000 \mathrm{rpm}$ for $5 \mathrm{~min}$. The clear supernatant was transferred to a clean tube and dried using a stream of nitrogen gas. The residue was re-dissolved in $200 \mu \mathrm{L}$ sample buffer (from the AVMs ELISA Kit) and vortexed for 2 min.

Sediment: $4 \mathrm{~mL}$ acetonitrile was added to $2 \mathrm{~g}$ sediment and homogenized for $10 \mathrm{~min}$. A total of $0.05 \mathrm{~g} \mathrm{NaCl}$ and $0.2 \mathrm{~g} \mathrm{MgSO}_{4}$ was then added. The mixture was immediately shaken to help reduce the development of aggregates and then centrifuged at 4,000 rpm for $12 \mathrm{~min}$. The clear supernatant was transferred to a clean tube and dried using a stream of nitrogen gas. The residue was re-dissolved in $1 \mathrm{~mL}$ sample buffer and vortexed for $2 \mathrm{~min}$.

Animal and plant: A $1 \mathrm{~g}$ sample of animal tissue (or a $2 \mathrm{~g}$ plant tissue sample) and $4 \mathrm{~mL}$ acetonitrile were mixed and homogenized. If the tissues were less than $1 \mathrm{~g}$, samples were prepared by the ratio of 1:4 (sample quantity and acetonitrile). After 1 min extraction by vortexing, $0.05 \mathrm{~g} \mathrm{NaCl}$ and $0.2 \mathrm{~g} \mathrm{MgSO}_{4}$ were added to the mixture and immediately shaken. The mixture was then centrifuged at $4000 \mathrm{rpm}$ for $12 \mathrm{~min}$. All the liquid in the acetonitrile layer was transferred to a clean tube, and $100 \mu \mathrm{L}$ dimethyl sulfoxide was added to the tube. The mixture was then dried using a stream of nitrogen gas. The residue was re-dissolved in $900 \mu \mathrm{L}$ sample buffer (or $300 \mu \mathrm{L}$ for the plant sample) and vortexed for $2 \mathrm{~min}$.

\section{Ivermectin determination}

An AVMs ELISA Kit was used to quantitatively measure the IVM in all the samples. The operating steps were performed using the manufacturer's instructions (Batch Number: 289106 and 289120). The concentration of IVM was calculated based on a standard curve using the corresponding coefficient.

\section{Data processing}

Data of the IVM concentration in the different samples were first standardized using minmax method (Tan et al., 2005), and a single radar chart was created using the ggRadar function in the ggiraphExtra package of the R statistical software (R Core Team, 2016).

\section{Results}

\section{Establishment of the standard curves}

According to the results of preliminary experiments, two types of AVMs ELISA kits (low and high levels) were chosen to detect the samples at the different concentration levels. Two representative standard curves for the quantification of IVM are shown in Fig. 2.

The regression equation of the low level standard curve (Batch Number: 289106) with a yaxis value of $\mathrm{OD}_{450}$ and an $\mathrm{x}$-axis value of the standard concentration $(0,0.20,0.39,0.88,1.98$ $\left.\mathrm{ng} \cdot \mathrm{mL}^{-1}\right)$ was $\mathrm{y}=-0.3208 \mathrm{x}+1.7914\left(\mathrm{R}^{2}=0.9961\right)$. The regression equation of the high level standard curve (Batch Number: 289120), with a y-axis value of $\mathrm{OD}_{450}$ and an $\mathrm{x}$-axis value of standard concentration against the $\log _{10}\left(1.56,3.51,7.90,17.78,40.00 \mathrm{ng} \cdot \mathrm{mL}^{-1}\right)$ was $\mathrm{y}=-$ $1.6319 \mathrm{x}+3.3054\left(\mathrm{R}^{2}=0.9877\right)$.

\section{Distribution of Ivermectin in the water and sediment}


160

161

162

163

164

165

166

167

168

169

170

171

172

173

174

175

176

177

178

179

180

181

182

183

184

185

186

187

188

189

190

191

192

193

194

195

196

197

198

199

The concentration curve of IVM in the water is shown in Fig. 3. The concentration of IVM was $0.092 \mathrm{ng} \cdot \mathrm{mL}^{-1}$ at $0.5 \mathrm{~h}$ after oral administration. It decreased to $0.084 \mathrm{ng} \cdot \mathrm{mL}^{-1}$ one day later. The concentration reached its peak at $7 \mathrm{~d}\left(0.113 \mathrm{ng} \cdot \mathrm{mL}^{-1}\right)$ and $30 \mathrm{~d}\left(0.115 \mathrm{ng} \cdot \mathrm{mL}^{-1}\right)$. The concentration of IVM then gradually declined and reached a value of $0.076 \mathrm{ng} \cdot \mathrm{mL}^{-1}$ at $70 \mathrm{~d}$.

The concentration of IVM in the sediment reached $3.141 \mathrm{ng} \cdot \mathrm{g}^{-1}$ at $0.5 \mathrm{~h}$ and accumulated continuously to its peak of $3.863 \mathrm{ng} \cdot \mathrm{g}^{-1}$ at $30 \mathrm{~d}$. After that, the IVM concentration in the sediment also gradually declined and reached a value of $2.946 \mathrm{ng} \cdot \mathrm{mL}^{-1}$ at $70 \mathrm{~d}$, which was similar to the trend with IVM in the water (Fig. 4).

\section{Distribution of Ivermectin in the brocarded carp}

As shown in Fig. 5, the concentration of IVM in the muscle was $6.416 \mathrm{ng} \cdot \mathrm{g}^{-1}$ at $0.5 \mathrm{~h}$ after the oral administration, and the peak appeared at $1 \mathrm{~d}$ with an IVM concentration of $67.080 \mathrm{ng} \cdot \mathrm{g}^{-1}$. The concentration of IVM in the visceral mass was $218.613 \mathrm{ng} \cdot \mathrm{g}^{-1}$ at $0.5 \mathrm{~h}$. The concentration of IVM in the visceral mass declined sharply during the next two weeks. Its concentration reached $4.469 \mathrm{ng} \cdot \mathrm{g}^{-1}$ in the muscle and $6.683 \mathrm{ng} \cdot \mathrm{g}^{-1}$ in the visceral mass at $70 \mathrm{~d}$. It is worth noting that there was a second peak in the visceral mass between $30 \mathrm{~d}$ and $45 \mathrm{~d}$ with a value of 27.796 to $28.979 \mathrm{ng} \cdot \mathrm{g}^{-1}$.

\section{Distribution of Ivermectin in the Amazon sword plant}

The concentration curves of the IVM in the leaves and roots of the Amazon sword plants are shown in Fig. 6. The concentration of IVM in the plant leaves was $19.573 \mathrm{ng} \cdot \mathrm{g}^{-1}$ at $0.5 \mathrm{~h}$, and it then decreased to $14.397 \mathrm{ng}^{-\mathrm{g}^{-1}}$ at $7 \mathrm{~d}$. At $15 \mathrm{~d}$, the IVM concentration increased to 18.581 $\mathrm{ng} \cdot \mathrm{g}^{-1}$, and then remained relatively stable until $60 \mathrm{~d}$. At $70 \mathrm{~d}$, the IVM decreased to $14.040 \mathrm{ng} \cdot \mathrm{g}$ 1 in the leaves.

Compared to the leaves, the concentration of IVM in the plant roots exhibited a different trend, which reached a peak value of $38.584 \mathrm{ng} \cdot \mathrm{g}^{-1}$ at day 7 . An obvious decline was observed from day 7 to 15 , and IVM decreased to $28.622 \mathrm{ng} \cdot \mathrm{g}^{-1}$. Finally, the IVM concentration decreased to $21.140 \mathrm{ng} \cdot \mathrm{g}^{-1}$ at $70 \mathrm{~d}$.

\section{Distribution of Ivermectin in the mudsnails}

The concentration curve of IVM in the mudsnails is shown in Fig. 7. The concentration of IVM was determined to be $13.221 \mathrm{ng} \cdot \mathrm{g}^{-1}$ at $0.5 \mathrm{~h}$ and then reached a peak value of $24.987 \mathrm{ng} \cdot \mathrm{g}^{-1}$ at $7 \mathrm{~d}$. A decline to $13.441 \mathrm{ng} \cdot \mathrm{g}^{-1} \mathrm{was}$ observed from $7 \mathrm{~d}$ to $15 \mathrm{~d}$. From day 15 to 70 , elimination of the IVM was very slow, and the concentration remained approximately $13 \mathrm{ng} \cdot \mathrm{g}^{-1}$.

\section{Data analysis}

As described above, the concentration of IVM in the samples was completely different after treatment. Thus, for comparison, the drug concentrations in seven types of samples at eight points in time were standardized and presented as a radar chart (Fig. 8).

With the extension of the administration time, IVM was transferred between different agents in the aquatic micro-ecological system. In one day, IVM appeared in the visceral mass of the brocarded carp and the leaves of the Amazon sword plant. There were many exchanges between the different agents from 1 to 7 days. The drug then transferred to the water and sediment over the following days until the 60th day. IVM finally appeared in the mudsnails. 


\section{Discussion}

\section{Methods and micro-ecological system for the detection}

202 Oral administration was chosen to study the environmental fate of IVM in an aquatic system 203 to ensure that the experimental fish were dosed with the accurate amount. As a class of potent 204 anti-parasitic agent, the effective treatment dose of IVM is only $0.3 \mathrm{mg} \cdot \mathrm{kg}^{-1}$ body weight by oral 205 administration in freshwater aquatic organisms.

206 The immunochemical method was able to detect low levels of residue in the water, soil, and 207 plant and animal samples (Krotzky et al., 1995). ELISA is a type of easily used, rapid, sensitive 208 and specific method to quantitatively analysis of ultra micro amounts (Dixon-Holland et al., 209 1992; Khalil et al., 2011). So far, ELISA had been widely used to detect IVM (Katharios et al., 210 2004; Shi et al., 2006; Menozzi et al., 2015; Bernigaud et al., 2016).

211 Based on the culture pond, the constructed micro-ecological system simulated a natural 212 environment to study the fate of IVM during aquaculture. The results indicated that this system 213 works well and data obtained have a certain guiding significance to drug usage in the cultured 214 ponds. However, there are still some shortages of the system. It is a small scale farming system 215 and the experimental animals are small in size, which make it suitable for the research on drug 216 fate in water environment. And the pharmacokinetic study cannot be carried out for the internal 217 organs in this system.

\section{Distribution of IVM in the aquatic environment}

219 In this study, the reason that the concentration of IVM in the sediment was higher than that 220 in the water should be due to the hydrophobic properties of IVM and its high affinity to organic 221 matter (Bloom et al., 1993). After treatment, the IVM was quickly detected in both the water and sediment. This is consistent with reports that the IVM could rapidly diffuse from the water phase to the sediment particles (Löffler et al., 2005).

In addition, two concentration peaks of IVM appeared in the water and sediment. First, it

226

227

228

229

230

231 appeared at $0.5 \mathrm{~h}$ after treatment. When the drug was given, part was immediately excreted by the gut to the aquatic environment for the nervous swimming of the fish and their gut cleaning. It was similar to the report that only $30 \%$ of IVM orally administered in salmon was measured in the muscle, blood, kidney and liver (Høy et al., 1990). After that, the second peak appeared at 30 $\mathrm{d}$ in both water and sediment, followed by a decline in the concentration of IVM in the aquatic organisms (including fish, mudsnails and plants). Thus, we deduced that both the water and sediment were crucial agents for the transfer of IVMs in aquatic system. In addition, IVM accumulated in the aquatic environment for a long time.

The IVM sorption to the sediment played a key role in its environmental fate (Prasse et al., 2009). In this study, IVM was quickly found in the sediment, and it remained for a long time (more than 70 days), which was similar to previous studies (Davies et al., 1998; Mougin et al., 2003; Wu et al., 2012). The reason for its persistence could be due to its rapid sorption and difficultly in desorbing from the soil (Rath et al., 2016). The long-term accumulation of IVM in an aquaculture environment was recognized as the diffusion sources of pollutants affecting ecosystems for its direct damage on non-target organisms and potential negative impact to 
240

241

242

243

244

245

246

247

248

249

250

251

252

253

254

255

256

257

258

259

260

261

262

263

264

265

266

267

268

269

270

271

272

273

274

275

276

277

278

279

sensitive ones (Burridge et al., 2010). The deposition of IVM will be considered to be cumulative over the period of excretion and deposition, and the levels found in the sediment will represent the cumulative total at the end of the deposition following treatment (Davies et al., 1998).

\section{Distribution of IVM in organisms}

Biocondensation refers to the ability of organisms to attain high-level concentrations of chemicals through transportation and accumulation in the food chain. The concentrations of chemicals obviously increase when it accumulates in a type of organism. In this study, we detected the transfer of IVM between several different types of organisms, including fish, plants and mudsnails in the closed simulated aquatic micro-ecological system.

For oral administration, the concentration of IVM in the visceral mass was higher than in the muscle during the first days. The concentrations of IVM in the muscle accumulated quickly and reached a peak at $1 \mathrm{~d}$. This result was similar to the pharmacokinetics research on IVM in Salvelinus leucomaenis (Han et al., 2014) and Oncorhynchus mykiss (Kang et al., 2015), which indicated that IVM had a secondary or multiple accumulation peaks in plasma, liver and kidney in $72 \mathrm{~h}$ after oral administration or i.p. injection. It was thought to be caused by multiple absorption of the intestinal-hepatic circulation and the gastrointestinal tract. However, this phenomenon is completely different from the mechanism caused by environmental drug exchange and accumulation after 30-45 days in this study. This phenomenon might be caused by the biocondensation of IVM from the water and sediment to the main organisms in the system. It was different from the one peak found in terrestrial animals (Vokřál et al., 2019). So far, there have been no reports on the occurrence of secondary accumulation peaks in organisms caused by long-term residues in aquaculture environments.

Chen et al. (2007) reported that E. amazonicus could adsorb substantial amounts of Ciprofloxacin (CPFX), especially by its leaves. IVM also appeared in the leaves of $E$. amazonicus within a short time in this study, which indicates that the leaves of E. amazonicus can adsorb some drugs. IVM accumulated to a higher level in the roots than in the leaves of the aquatic plants. It was hypothesized that the drug in the aquatic plants was primarily from the sediment because the concentration of IVM was higher in the roots than in the leaves.

Mudsnails played an important role in regulating the structure of an aquatic ecological system (USEPA, 2009), and they are usually used as important biological indicators of ecological toxicology (Volker et al., 2014; Liu et al., 2015) In this study, IVM appeared at $0.5 \mathrm{~h}$ and remained at a high level in the mudsnails for more than 70 days. That may be related to the drug residue in the sediment, which served as the food for the mudsnails (Guo et al., 1997). The concentration of IVM in the mudsnails, which can absorb pollutants from water bodies (Cai et al., 2013), could indicate the drug level in the whole aquatic system.

\section{Conclusions}

In summary, we simulated an aquatic micro-ecological system and evaluated the fate of IVM in the environment and several types of organisms in this study. IVM could accumulate and be distributed in the water, sediment, fish, plants and mudsnails, and there was an obvious change of IVM concentration in different media over time. 


\section{Acknowledgements}

281 This work was supported by Central Public-interest Scientific Institution Basal Research Fund,

282 HRFRI (NO. HSY201705M), Central Public-interest Scientific Institution Basal Research

283 Fund, CAFS (NO. 2017HY-ZD1009) and Special Fund for Agro-scientific Research in the

284 Public Interest (Grant No. 201203085).

285 References

286 Bernigaud C, Fang F, Fischer K, Lespine A, Aho LS, Dreau D, Kelly A, Sutra JF, Moreau

287 F, Lilin T, Botterel F, Guillot J, Chosidow O. 2016. Preclinical study of single-dose

288 moxidectin, a new oral treatment for scabies: efficacy, safety, and pharmacokinetics compared to 289 two-dose ivermectin in a porcine model. Plos Negl Trop Dis online, doi:

290 10.1371/journal.pntd.0005030.

291 Bloom RA, Matheson JC. 1993. Environmental assessment of avermectins by the US food and 292 drug administration. Vet Parasitol 48(1-4), 281-294.

293 Burridge L, Weis JS, Cabello F, Pizarro J, Bostick K. 2010. Chemical use in salmon

294 aquaculture: A review of current practices and possible environmental effects. Aquaculture

295 306(1-4): 7-23.

296 Cai YJ, Jiang JH, Zhang L, Chen YW, Gong ZJ. 2013. Structure of macro-zoobenthos in lakes

297 along the Yangtze River and relationships with environmental characteristics. Acta Ecologica

298 Sinica 33(16): 4985-4999.

299 Chen JF, Zhou XZ, Nie XP, Jiang TJ. 2007. Fate of Ciprofloxacin in a simulated micro-

300 cosmos system by different exposure ways. Acta Ecologica Sinica 27(12): 5300-5307.

301 Davies LM, Gillibrand PA, McHenery JG, Rae GH. 1998. Environmental risk of ivermectin

302 to sediment dwelling organisms. Aquaculture 163: 29-46.

303 Dixon-Holland DE. 1992. ELISA and its application for residue analysis of antibiotics and 304 drugs in products of animal origin, Springer US.

305 Forster B, Boxall A, Coors A, Jensen J, Liebig M, Pope L, Moser T, Rombke J. 2011. Fate 306 and effects of ivermectin on soil invertebrates in terrestrial model ecosystems. Ecotoxicology

307 20(1): 234-245.

308 Garric J, Vollat B, Duis K, Pery A, Junker T, Ramil M, Fink G, Ternes TA. 2007. Effects of 309 the parasiticide ivermectin on the cladoceran Daphnia magna and the green alga

310 Pseudokirchneriella subcapitata. Chemosphere 69(6), 903-910.

311 Geary TG. 2005. Ivermectin 20 years on: maturation of a wonder drug. Trends Parasitol 21(11), 312 530-532.

313 Guo MX, Lin YH. 1997. River snail Cipangopaludina Cathayensis as an indicator for toxicity

314 and bioabailability of heavy metals in sediment. Environment and Exploitation 12(2): 8-11.

315 Han B, Yang HB, Wang D, Lu TY. 2014. Pharmacokinetics of ivermectin in Salvelinus

316 leucomaenis following two ways of administration. Agricultural Science \& Technology 15(4):

317 678-682, 687.

318 Høy T, Horsberg TE, Nafstad I. 1990. The disposition of ivermectin in Atlantic salmon (Salmo

319 salar). Pharmacol Toxicol 67(4): 307-312. 
320

321

322

323

324

325

326

327

328

329

330

331

332

333

334

335

336

337

338

339

340

341

342

343

344

345

346

347

348

349

350

351

352

353

354

355

356

357

358

359

Johnson SC, Kent ML, Whitaker DJ, Margolis L. 1993. Toxicity and pathological effects of orally administered ivermectin in Atlantic, Chinook and Coho salmon and steelhead trout. Dis Aquat Organ 17, 101-105.

Kang SY, Han B, Wang D, Lu TY. 2015. Pharmacokinetics of ivermectin in oncorhynchus mykiss following two ways of adminisitration. Chinese agricultural science bulletin, 31(2): 101106.

Katharios P, Pavlidis M, Iliopoulou-Georgudaki J. 2004. Accumulation of ivermectin in the brain of sea bream, Sparus aurata after intraperitoneal administration. Environ Toxicol Pharmacol 17(1): 9-12.

Khalil IF, Alifrangis M, Recke C, Hoegberg LC, Ronn A, Bygbjerg IC, Koch C. 2011. Development of ELISA-based methods to measure the anti-malarial drug chloroquine in plasma and in pharmaceutical formulations. Malar J 10(1): 249.

Krotzky AJ, Zeeh B. 1995. Immunoassays for residue analysis of agrochemicals: Proposed guidelines for precision, standardization and quality control (Technical Report). Pure and applied chemistry 67(12): 2065-2088.

Liu H, Wang Q, Wang WM, Tan JK. 2015. The oxidative stress of copper on liver of river snail Cipangopaludina cahayensis in the presence of two kinds of organic acids. Asian Journal of Ecotoxicology 10(2): 306-312.

Löffler D, Römbke J, Meller M, Ternes TA. 2005. Environmental fate of pharmaceuticals in water/sediment systems. Environ Sci Technol 39(14): 5209-5218.

Menozzi A, Bertini S, Turin L, Serventi P, Kramer L, Bazzocchi C. 2015. Doxycycline levels and anti-Wolbachia antibodies in sera from dogs experimentally infected with Dirofilaria immitis and treated with a combination of ivermectin/doxycycline. Vet Parasitol 209(3-4): 281284.

Mougin C, Kollmann A, Dubroca J, Ducrot PH, Alvinerie M, Galtier P. 2003. Fate of veterinary medicine ivermenctin in soil. Environ Chem Lett 1, 131-134.

Omura S. 2008. Ivermectin: 25 years and still going strong. Int J Antimicrob 31:91-98.

Omura S, Crump A. 2014. Ivermectin: panacea for resource-poor communities? Trends Parasitol 30:445-455.

Palmer R, Rodger H, Drinan E, Dwyer C, Smith PR. 1987. Preliminary trials on the efficacy of ivermectin against parasitic copepods of Atlantic salmon. Bulletin European Association Fish Pathologists 7, 47-54.

Prasse C, Lffler C, Ternes TA. 2009. Environmental fate of the anthelmintic ivermectin in an aerobic sediment/water system. Chemosphere 77(10): 1321-1325.

Rath S, Pereira LA, Bosco SMD, Maniero MG, Fostier AH, Guimaraes JR. 2016. Fate of ivermectin in the terrestrial and aquatic environment: mobility, degradation, and toxicity towards Daphnia similis. Environ Sci Pollut Res Int 23(6): 5654-5666.

Sanderson H, Laird B, Pope L, Brain R, Wilson C, Johnson D, Bryning G, Peregrine AS, Boxall A, Solomon K. 2007. Assessment of the environmental fate and effects of ivermectin in aquatic mesocosms. Aquat Toxicol 85(4): 229-240.

Peer) reviewing PDF | (2019:06:38294:3:0:NEW 29 Aug 2019) 
360 Shi W, He J, Jiang H, Hou X, Yang J, Shen J. 2006. Determination of multiresidue of 361 avermectins in bovine liver by an indirect competitive ELISA. Journal of agricultural and food 362 chemistry 54(17): 6143-6146.

363 Tan P, Steinbach M, Kumar V. 2005. Introduction to data mining. Addison Wesley.

364 Ucan-Marin F, Ernst W, O'Dor RK, Sherry J. 2012. Effects of food borne ivermectin on 365 juvenile Atlantic salmon (Salmo salar L.): survival, growth, behavior, and physiology.

366 Aquaculture 334-337: 169-175.

367 USEPA. National recommended water quality criteria. 2009. Washington DC: US EPA, Office 368 of Water, Office of Science and Technology.

369 Vokřál I, Michaela Š, Radka P, Jiř́́ L, Lukáš P, Dominika S, Lenka S. 2019. Ivermectin

370 environmental impact: Excretion profile in sheep and phytotoxic effect in Sinapis alba.

371 Ecotoxicol Environ Saf 169, 944-949.

372 Volker C, Graf T, Schneider I, Oetken M, OehImann J. 2014. Combined effects of silver

373 nanoparticles and 17 $\alpha$-ethinylestradiol on the freshwater mudsnail Potamopyrgus antipodarum.

374 Environ Sci Pollut Res Int 21(18): 10661-10670.

375 Wall R, Strong L. 1987. Environmental consequences of treating cattle with the antiparasitic

376 drug ivermectin. Nature 327, 418-421.

377 Wu H, Jiang M, Peng ZX, He L. 2012. Research on the degradation of ivermectin and its acute 378 toxicity to seven aquatic organisms. Acta Hydrobiologica Sinica 36(5): 965-970.

379 Yang XL. 2005. New fishery drugs manual, Beijing: China agriculture press, 252. 
Figure 1

Simulated aquatic micro-ecological system

The system consists of water, sediment, brocarded carp, mudsnails and Amazon sword plants.

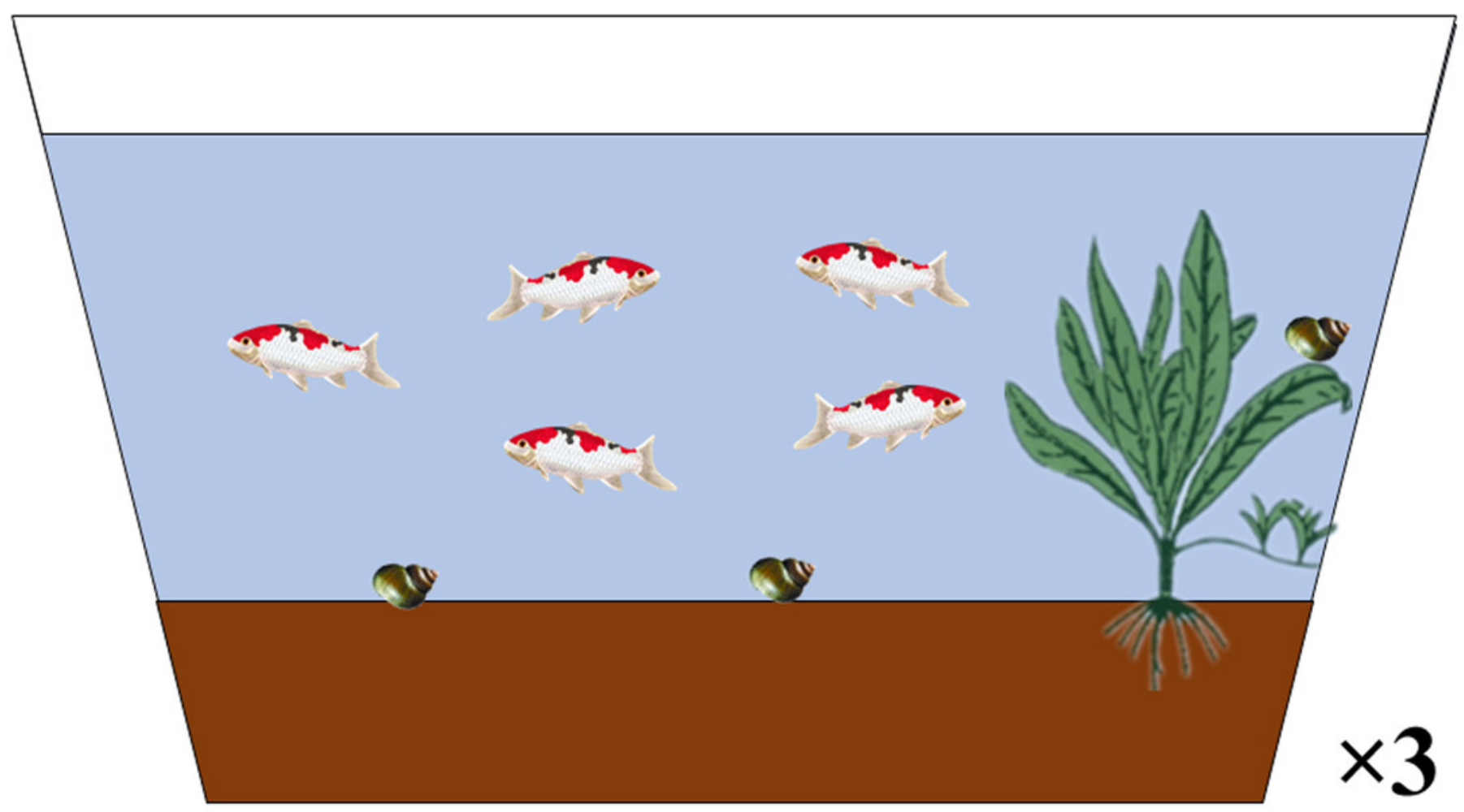


Figure 2

The standard curve of IVM at different standard concentrations

(A)The low level standard curve. The standard curve with a $y$-axis value of $\mathrm{OD}_{450}$ and an $\mathrm{x}$ axis value of the standard concentration $(0,0.20,0.39,0.88,1.98 \mathrm{ng} / \mathrm{mL})$. (B) The high level standard curve. The standard curve with a y-axis value of $\mathrm{OD}_{450}$ and an $\mathrm{x}$-axis value of the standard concentration against the $\log _{10}(1.56,3.51,7.90,17.78,40.00 \mathrm{ng} / \mathrm{mL})$. 

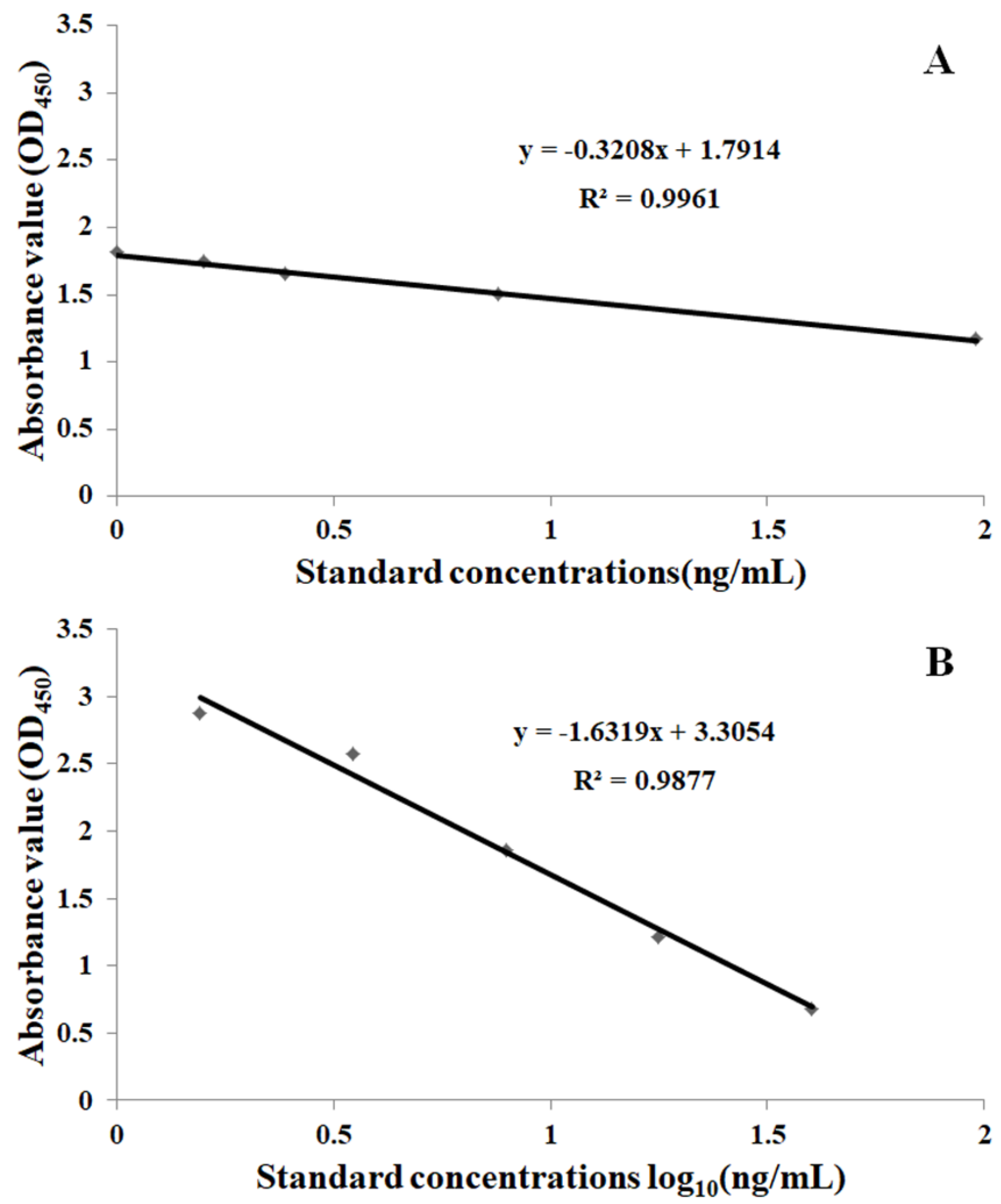
Figure 3

IVM concentrations in the water

The curve indicates the change of IVM concentrations in the water from $0.5 \mathrm{~h}$ to $70 \mathrm{~d}$ after the single oral administration.

Water

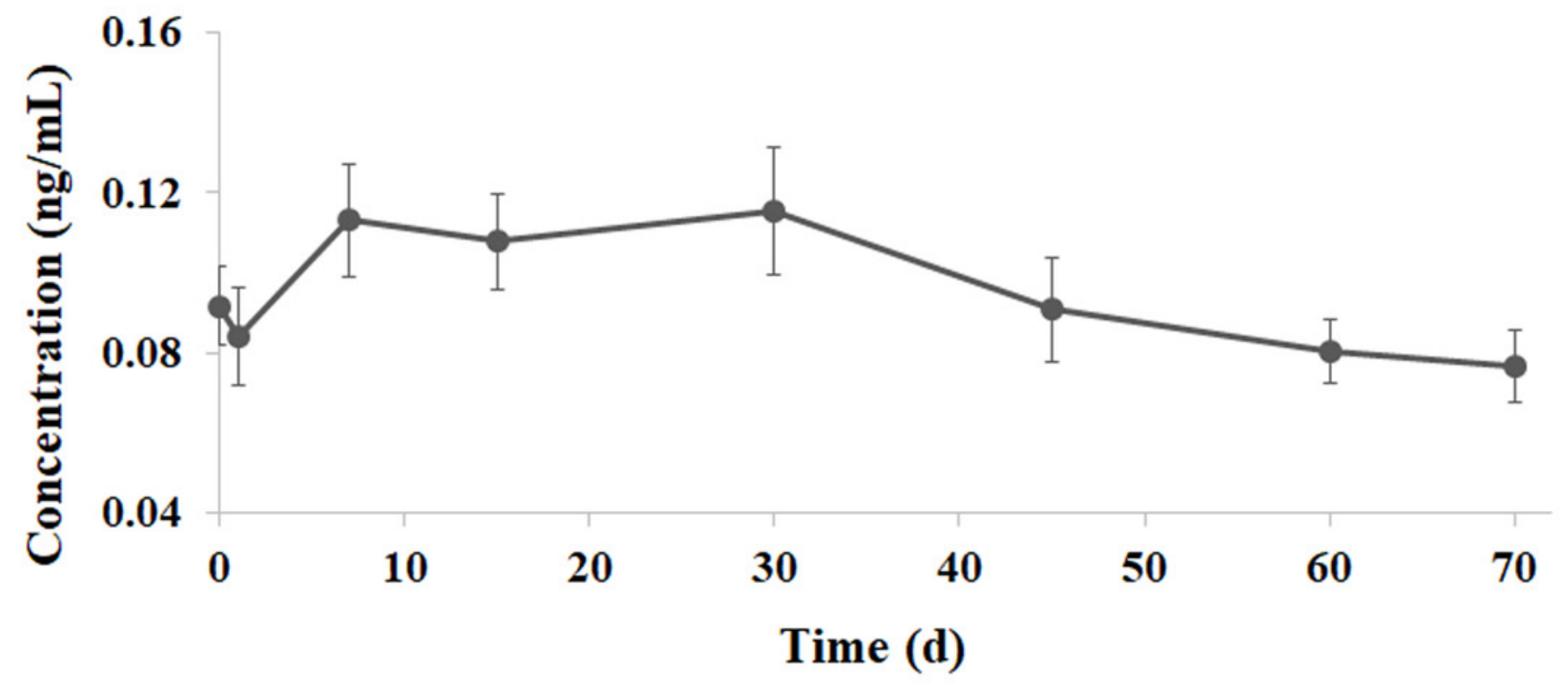


Figure 4

IVM concentrations in the sediment

The curve indicates the change of IVM concentrations in the sediment from $0.5 \mathrm{~h}$ to $70 \mathrm{~d}$ after the single oral administration.

\section{Sediment}

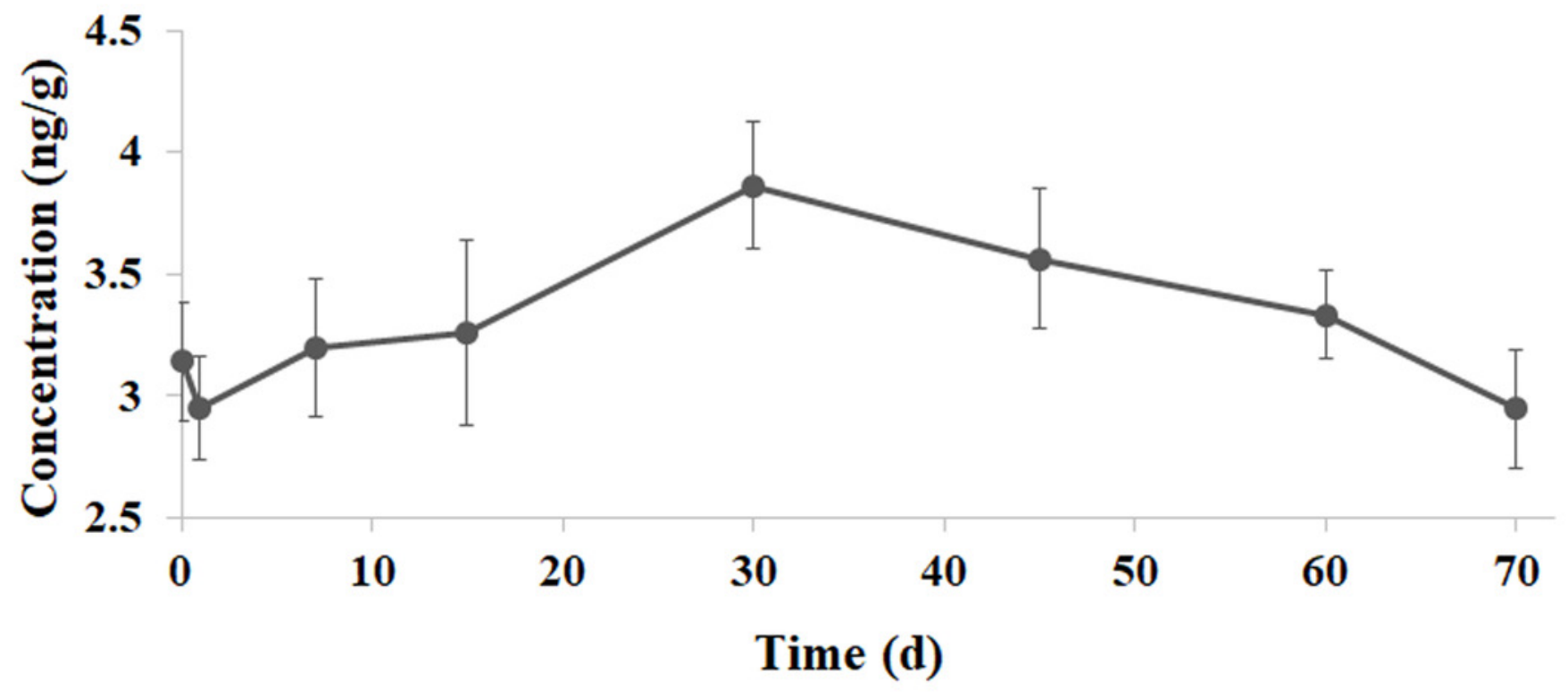


Figure 5

IVM concentrations in the visceral mass and muscle of brocarded carp

The curve indicates the change of IVM concentrations in the visceral mass and muscle of brocarded carp from $0.5 \mathrm{~h}$ to $70 \mathrm{~d}$ after the single oral administration.

Fish

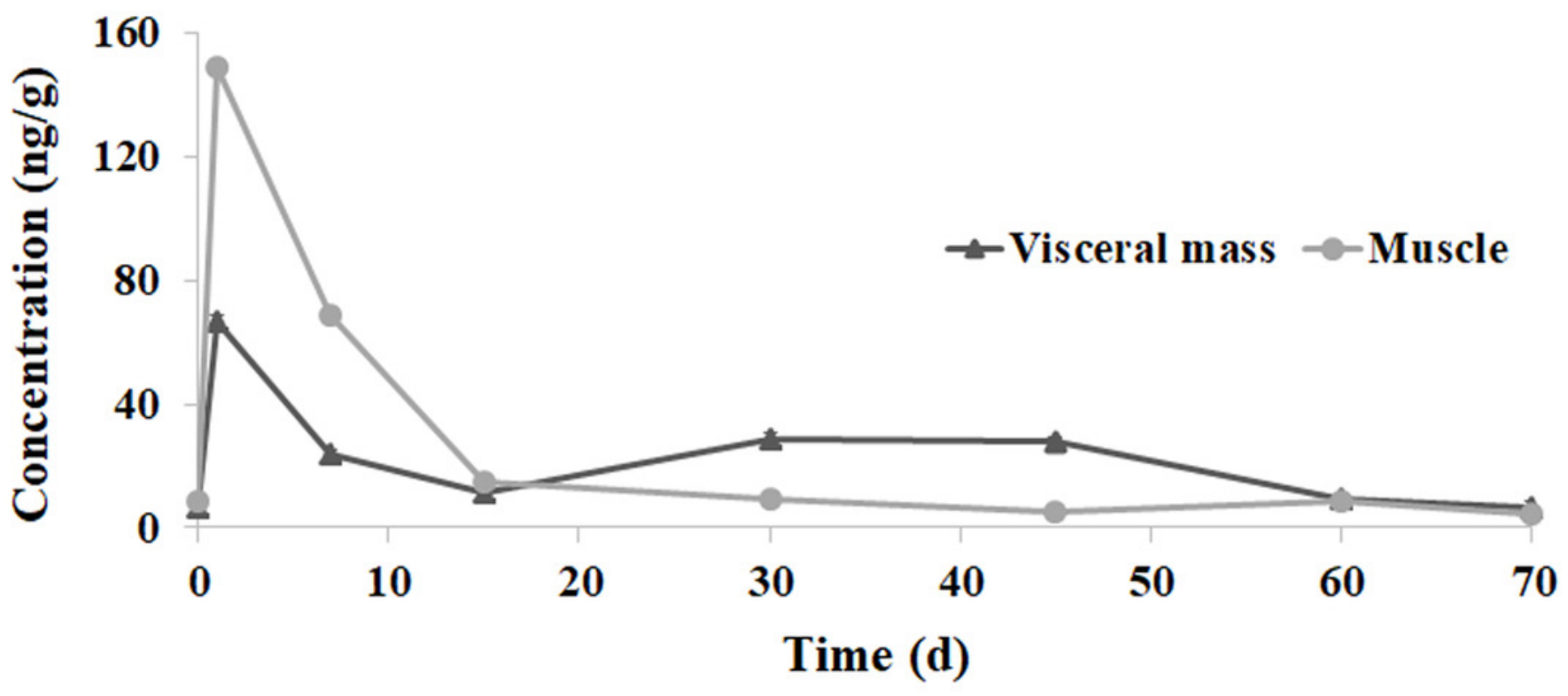


Figure 6

IVM concentrations in the Amazon sword plant

The curve indicates the change of IVM concentrations in root and leaves of the Amazon sword plants from $0.5 \mathrm{~h}$ to $70 \mathrm{~d}$ after the single oral administration.

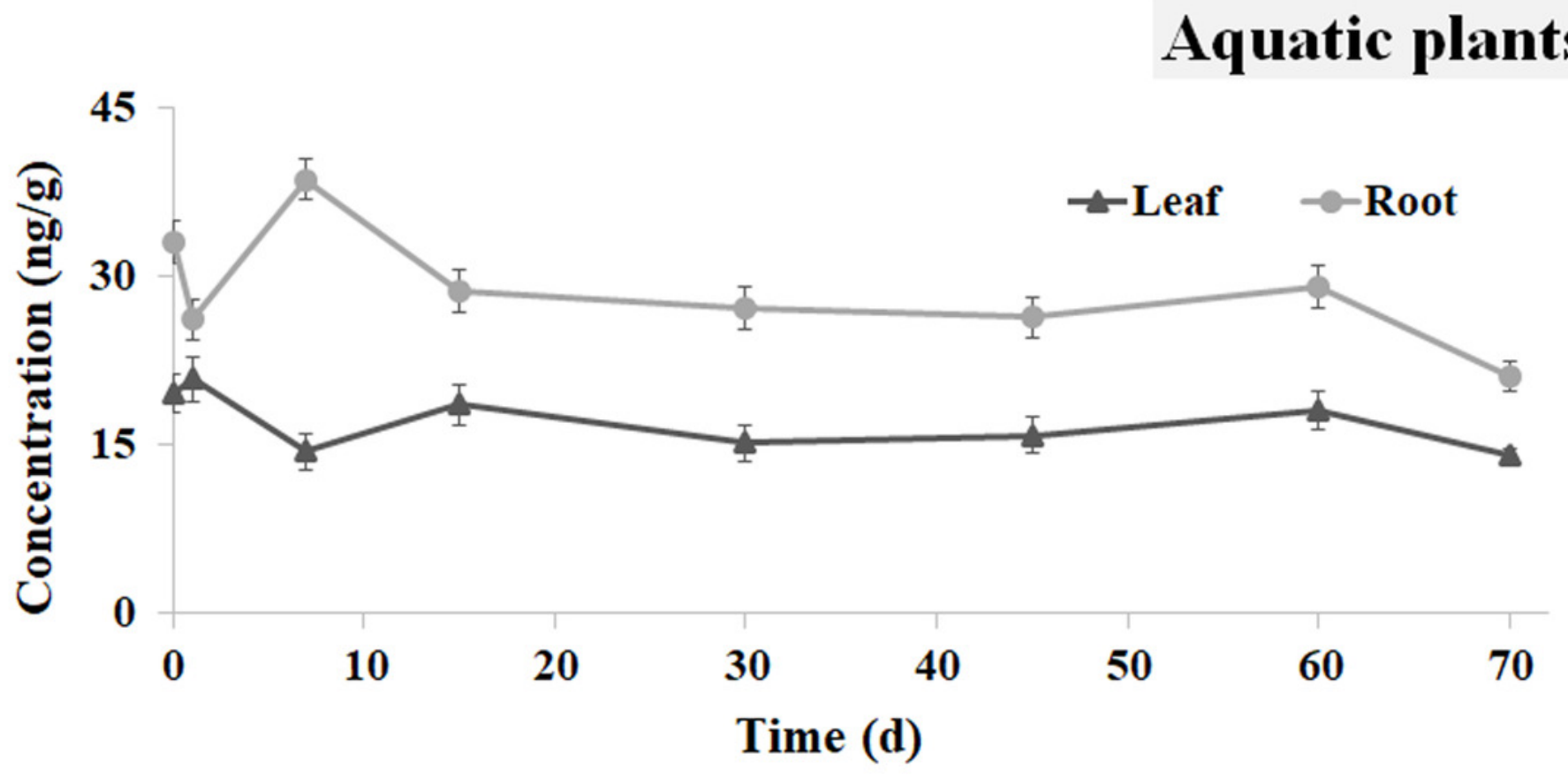


Figure 7

IVM concentrations in the mudsnails

The curve indicates the change of IVM concentrations in the soft tissue of the mudsnails from $0.5 \mathrm{~h}$ to $70 \mathrm{~d}$ after the single oral administration.

\section{Mudsnails}

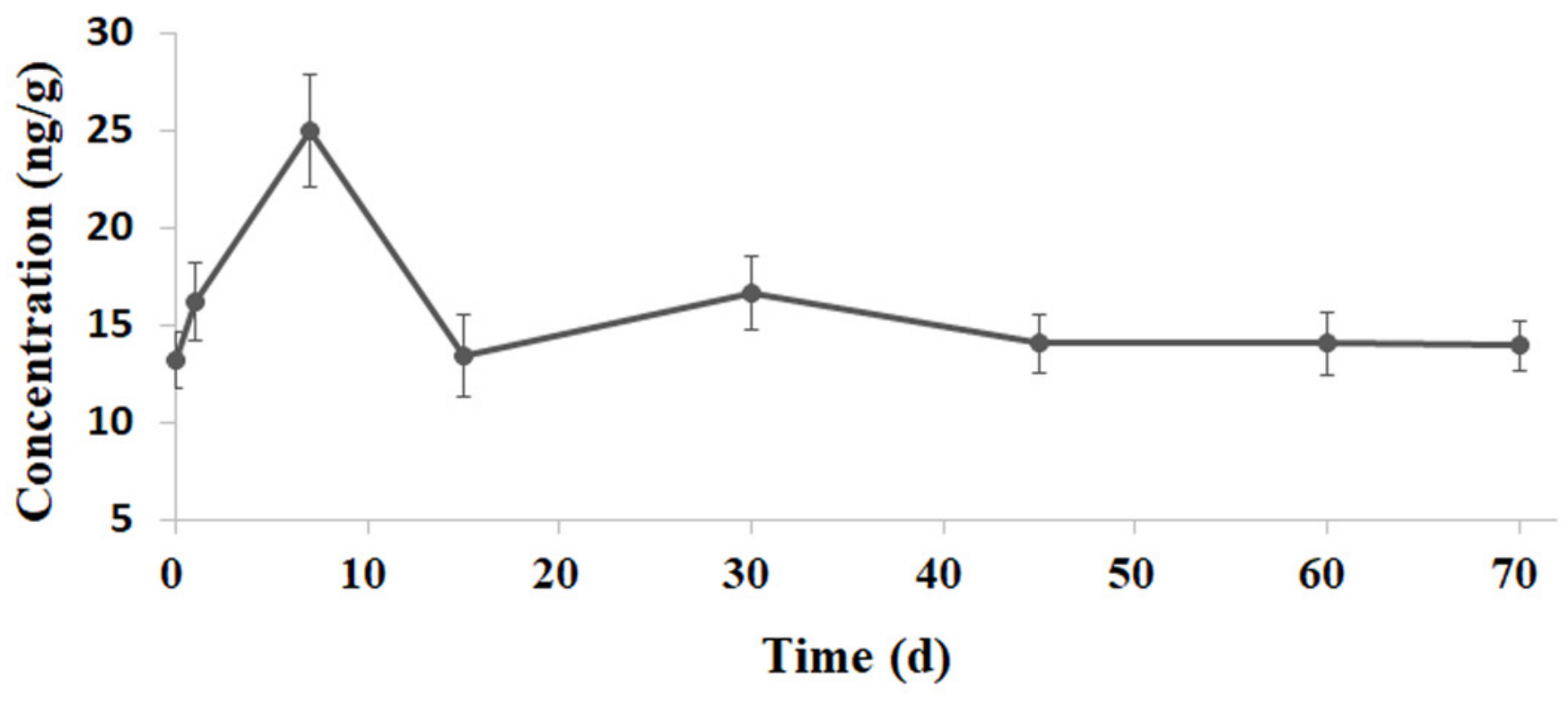


Figure 8

Radar chart for the IVM concentrations in the aquatic micro-ecological system (consisting of water, sediment, fish, plants and mudsnails)

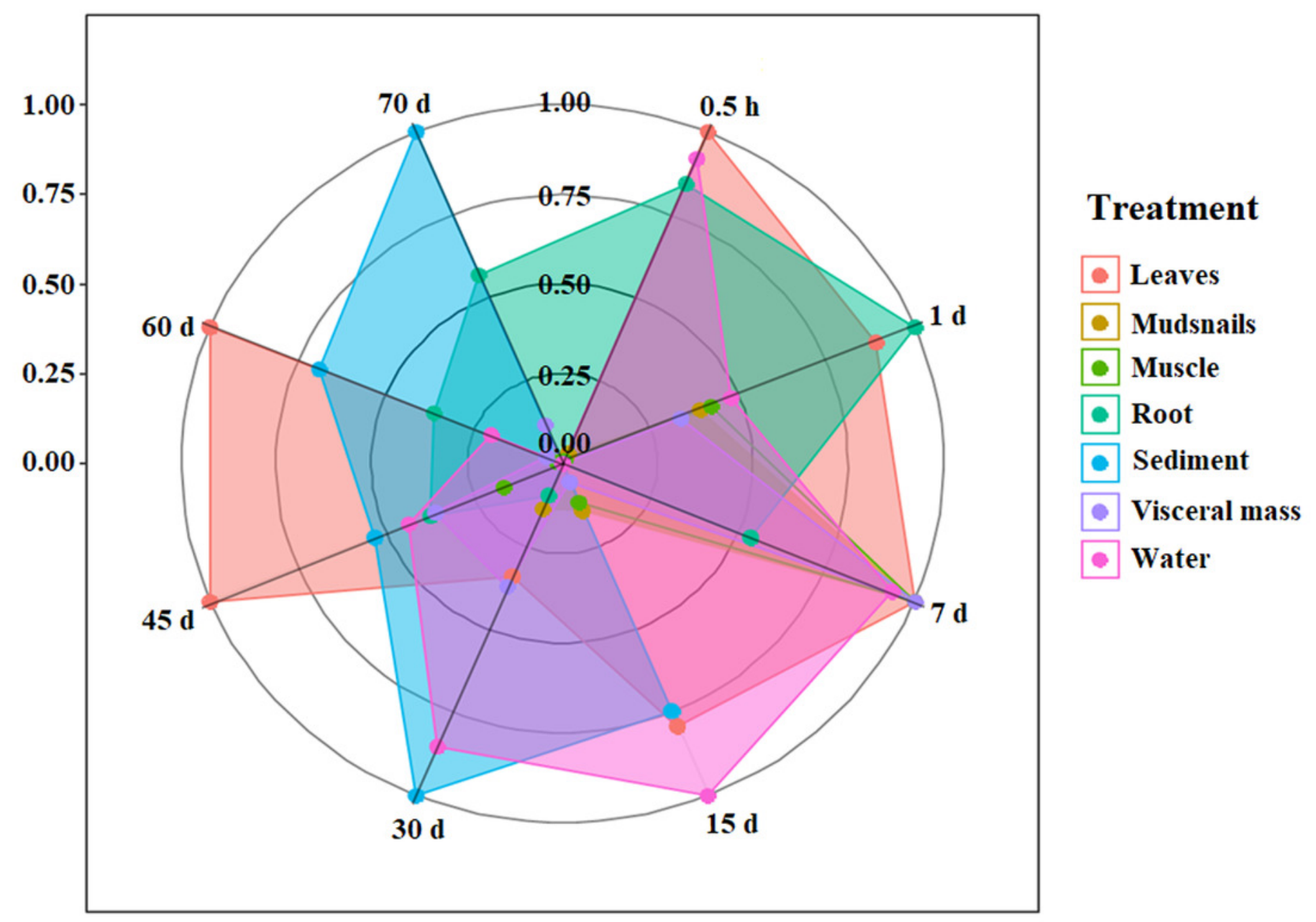

